\title{
Comparison of Greenhouse and Field Testing to Identify Wheat Resistant to Tan Spot
}

C. K. Evans, Research Associate, Department of Plant Pathology, University of Minnesota, St. Paul 55108; and R. M. Hunger, Professor, and W. C. Siegerist, Senior Agriculturist, Department of Plant Pathology, Oklahoma State University, Stillwater 74078-9947

\begin{abstract}
Evans, C. K., Hunger, R. M., and Siegerist, W. C. 1999. Comparison of greenhouse and field testing to identify wheat resistant to tan spot. Plant Dis. 83:269-273.

Incorporation of tan spot resistance into adapted wheat (Triticum aestivum) lines requires screening procedures in the greenhouse and field that correctly identify reaction to tan spot. This study compares greenhouse (seedling) and field (adult plants) testing of wheat lines for reaction to tan spot following inoculation with conidia by Pyrenophora tritici-repentis. Mistirrigation was used to provide adequate moisture for infection by $P$. tritici-repentis in the greenhouse and in the field. Reaction of seedlings to tan spot in the greenhouse was measured by lesion length. Area under the disease progress curve (AUDPC) was used to determine reaction in the field. The effect of tan spot on grain yield and kernel weight was determined by comparing inoculated with fungicide-sprayed split-plot values. In greenhouse tests, lesion length ranged from 1.2 to $4.1 \mathrm{~mm}$. Lesions were $1.2 \mathrm{~mm}$ long on Red Chief, a tan spot-resistant check. Lesions were $3.6 \mathrm{~mm}$ long on TAM 105, a tan spot-susceptible check. Four breeder lines had levels of seedling (greenhouse) resistance nearly equal to that of Red Chief. Ranks of lesion length and field assessments of the AUDPC were significantly correlated ( $r=0.75$ to $0.93, P \leq$ $0.05)$. Thus, greenhouse assessment was useful for screening large numbers of wheat genotypes for reaction to tan spot and identifying selected entries for further screening in the field. Mean grain yield from $P$. tritici-repentis inoculated plots was approximately $15 \%$ less than yield from fungicide-sprayed plots. Kernel weight was reduced an average of 7 and $13 \%$ at two field locations.
\end{abstract}

Additional keywords: breeding for disease resistance

Pyrenophora tritici-repentis (Died.) Drechs. (anamorph: Drechslera triticirepentis (Died.) Shoemaker) is a fungal foliar pathogen of many gramineous species (19-24) and a foliar and seed pathogen of wheat (Triticum spp.) that causes tan spot on leaves and stems, and pink smudge of grain $(12,15,32,38)$. Tan spot is capable of causing significant yield and grain quality losses in spring and winter wheat (Triticum aestivum L.) $(16,30,33)$, and it occurs in all major wheat producing regions of the United States and the world (39). Infection of wheat by conidia of $P$. tritici-repentis requires a postinoculation wet period of 6 to $48 \mathrm{~h}$ and is influenced by temperature as well as host genotype $(17,18)$. Additional factors that can influence incidence and severity of tan spot on wheat include the age of wheat foliage $(8,31)$, toxin production by $P$. triticirepentis isolates $(3,6,26-28,37)$, the aggressiveness and type of lesion produced

Corresponding author: R. M. Hunger

E-mail: rmh@okway.okstate.edu

Accepted for publication 7 December 1998.

Publication no. D-1999-0115-02R

(C) 1999 The American Phytopathological Society by the isolate(s) of $P$. tritici-repentis $(23,25,26)$, and levels of residue left by different tillage systems $(1,4,41)$. Assessments of wheat lines in separate breeding programs based on variations of these different factors and how they could affect the outcome of a screening procedure to identify resistance to $P$. tritici-repentis are unknown. Hence, it would be useful to characterize screening procedures that assess breeding lines of wheat based upon the repeatability of reaction to $P$. triticirepentis between or among procedures.

Greenhouse and field procedures to screen wheat lines for reaction to tan spot have been reported $(1,7,11,29)$, but none have compared directly the repeatability of greenhouse and field screening methods. Two methods of inoculating wheat in the field have been reported that involve inoculation with oat kernels or wheat straw infested with the fungus $(1,29)$. With either method, inoculum is distributed within or between wheat plots. As pseudoperithecia mature, ascospores are discharged that initiate tan spot infections on wheat leaves. The advantage of these methods of inoculation is the ease of production and application of $P$. tritici-repentis inoculum. However, maturation of pseudoperithecia and release of ascospores depend on climatic conditions, which can be unfavorable in some seasons. This means release of primary inoculum is difficult to time and quantify. Another reported method of field inoculation uses conidia, conidiophores, and mycelium as inoculum that is applied directly to wheat plants $(9,29)$. The main advantage of using this method is that inoculum can be applied at specific stages of crop development during favorable climatic conditions. However, this method requires more effort to produce, quantify, and apply inoculum onto foliage. Greenhouse screening coupled with field screening provide breeders with more cycles of screening in which to gain additional information regarding a wheat breeding line's potential as a source of resistance to $P$. tritici-repentis. The primary objective of this study was to compare greenhouse and field reactions to tan spot of wheat lines inoculated with conidia of $P$. tritici-repentis when mist-irrigation was used to facilitate conditions favorable for infection. A second objective was to quantify yield losses from tan spot in the field by comparing yields obtained from fungicide-sprayed and $P$. tritici-repentis inoculated split-plots.

\section{MATERIALS AND METHODS}

Inoculum preparation. Three $P$. triticirepentis isolates collected from wheat fields near Altus (91ALA1), Guymon (91GYA3), and Braman (91RBB6), Oklahoma (10) were used in these experiments. Suspensions of conidia from the isolates were produced following a previously published technique (10). The technique involves growing the fungus in potato dextrose broth, followed by removal, comminution, and inoculation into liquid clarified V8 juice agar (CV8). After $48 \mathrm{~h}$ of growth in the dark, the fungus is exposed to alternating periods of light and dark that stimulate the production of conidiophores and conidia in a lawn covering the entire surface of the colony. Conidia are removed using a directed stream of water from a wash-bottle. Suspensions of conidia were obtained ranging in purity from 92 to $100 \%$; the other propagules when detected were hyphal fragments or conidiophores. Germination of P. triticirepentis conidia on the surface of water agar was monitored in all trials at the time of inoculation. Conidia were inoculated onto water agar media. Germination of 100 spores selected arbitrarily was 
counted after $12 \mathrm{~h}$ using a stereomicroscope.

Greenhouse screening procedure. Eight wheat lines (Table 1) from the 1992 Southern Regional Performance Nursery (SRPN) plus the wheat cultivars Red Chief (tan spot-resistant check) and TAM 105 (tan spot-susceptible check) were evaluated in this study. Ten seeds of each line or cultivar were planted in hills in a pasteurized soil mix (soil, sand, and peat moss in a 1:1:1 ratio by volume) contained in wooden flats $(51 \times 38 \times 7 \mathrm{~cm})$. Entries were planted in a randomized complete block design $(10$ seeds per hill $=$ one replicate per flat), with two replicates in the first test and four in the second. Greenhouse temperatures during the tests ranged from 20 to $23^{\circ} \mathrm{C}$. Inoculum consisted of a mixture of equal amounts of conidia produced from the three single ascospore isolates of $P$. tritici-repentis (final concentration $=1,000$ conidia $\mathrm{ml}^{-1}$ with 1 drop of Tween 20 per $100 \mathrm{ml}$ ). First leaves (first trial) or third leaves (second trial) were inoculated when fully expanded using a DeVilbiss sprayer (model 5601 D) until incipient runoff. Plants were placed in a mist chamber $1 \mathrm{~h}$ after inoculation. The mist chamber provided near $100 \%$ relative humidity at $20^{\circ} \mathrm{C}$. After $24 \mathrm{~h}$ in the mist chamber, plants were transferred to greenhouse benches. The length of the longest lesion in the middle half of the first leaf or third leaf was measured after 8 days. The inoculum concentration used and the timing of lesion measurement facilitated lesion expansion while avoiding coalescing of lesions. A dial caliper with an accuracy range of $\pm 0.05 \mathrm{~mm}$ was used for measuring lesions. One measurement was made on four separate leaves of four plants from each hill exhibiting the most pronounced tan spot symptoms. Measurements were made from the border of the visible edge of the longest dimension of a chlorotic or necrotic lesion, which generally was oriented parallel with the leaf axis. Statistical analyses were conducted on the mean of the four measurements made per wheat line or cultivar. Data from both tests of the 1992 SRPN were analyzed separately and then were combined for final analysis using the GLM procedure of the SAS statistical program (SAS Institute, Cary, NC). Mean separations were conducted using Fisher's least significant difference (FLSD) test.

Field plot design and inoculation. The field tests were done in the 1992-93 season using the same 10 wheat lines and cultivars as in the greenhouse tests. Two tests were conduced, one at the Agronomy Research Station near Perkins, Oklahoma, and one at the Plant Pathology Research Farm near Stillwater, Oklahoma. The soil type at Perkins was a Teller loam. The soil type at Stillwater was an Easpur loam. Following soil testing at each location, fertilizer was applied for a yield goal of 2,016 $\mathrm{kg} \mathrm{ha}^{-1}$. Plots, which were separated from each other by a blank row, consisted of two rows on $22.8-\mathrm{cm}$ centers that were $1.52 \mathrm{~m}$ long. Each row was planted with $3.5 \mathrm{~g}$ of wheat seed. The field trial at Stillwater was seeded 28 September 1992, and the trial at Perkins was seeded 1 October 1992. The experimental design was a split-plot with four randomized blocks. Blocks were separated by an alley $1.52 \mathrm{~m}$ wide. The entire test was bordered on all sides with the wheat cultivar Cimmaron. The 10 wheat lines and cultivars were planted in main plots. The subplots were sprayed with propiconazole (Tilt; Novartis Corp., Greensboro, NC) or with conidia of $P$. tritici-repentis prepared as described earlier (10). A fiberglass sheet was placed at the midpoint of the plot when fungicide was applied to prevent the fungicide from drifting onto the tan spot-inoculated subplot. Plots were sprayed with a handsprayer at 187 liters ha $^{-1}$ using a solution containing $6.28 \mathrm{~g}$ of active ingredient per liter. Subplots at Stillwater and Perkins were sprayed with propiconazole on 26
March 1993 and on 2 April 1993, respectively. Thereafter, fungicide-treated subplots at each location were sprayed at 14 day intervals, a total of three times, to control tan spot and other foliar wheat diseases.

Plots were inoculated at Stillwater on 29 March 1993 and at Perkins on 9 April 1993. Inoculum concentration was adjusted to 3,000 conidia $\mathrm{ml}^{-1}$. The inoculum consisted of $93 \%$ conidia and $7 \%$ hyphal fragments and conidiophores. Thus, the concentration of propagules of $P$. triticirepentis in the inoculum suspension was $3,225 \mathrm{ml}^{-1}$ prepared as previously described. The growth stage of the 10 wheat genotypes at each location at the time of their inoculation ranged from Zadoks 31 to 32 scale (40). Petri dishes $(100 \times 15 \mathrm{~mm})$ containing water agar were placed in the middle of each plot prior to inoculation. After inoculation, the water agar plates were collected and incubated for $12 \mathrm{~h}$ in the dark. Percent germination was assessed from 100 conidia per dish selected arbitrarily. Following inoculation of plots at each location, mist-irrigation was applied to facilitate free moisture on wheat leaves, which is required for tan spot infection $(17,18)$. Plots at Stillwater were inoculated at $1500 \mathrm{~h}$, then received $20 \mathrm{~min}$ of mistirrigation at 1530, 1700, and $1800 \mathrm{~h}$. Rainfall started approximately $8.5 \mathrm{~h}$ after inoculation, and over the next 8 -h period, a total of $15 \mathrm{~mm}$ of precipitation fell. Conditions were cloudy for the entire following day, and continuous free moisture was present on wheat leaves for approximately $30 \mathrm{~h}$ following inoculation. At Perkins, plots were inoculated at $900 \mathrm{~h}$ and then misted for $30 \mathrm{~min}$ at 1030, 1300, 1800, and $2100 \mathrm{~h}$. The following day, $30 \mathrm{~min}$ of mistirrigation was applied at 830 and $1000 \mathrm{~h}$. Sky conditions at Perkins were clear.

Twenty-two days after inoculation, leaves showing tan spot symptoms were collected from each split-plot at both locations to confirm infection. Each leaf was

Table 1. Greenhouse ratings of tan spot lesion lengths and field assessments of the area under the disease progress curve (AUDPC) for eight lines from the 1992 Southern Regional Performance Nursery and two wheat cultivars

\begin{tabular}{|c|c|c|c|c|c|c|c|c|}
\hline \multirow{3}{*}{$\begin{array}{l}\text { Wheat lines } \\
\text { and cultivars } \\
\text { Red Chief }^{\mathrm{x}}\end{array}$} & \multicolumn{4}{|c|}{ Greenhouse ratings of lesion length $(\mathrm{mm})$ and rank } & \multicolumn{4}{|c|}{$\mathrm{AUDPC}^{\mathrm{v}}$ from field ratings and rank } \\
\hline & \multicolumn{2}{|c|}{ Experiment 1} & \multicolumn{2}{|c|}{ Experiment 2} & \multicolumn{2}{|c|}{ Perkins $^{w}$} & \multicolumn{2}{|c|}{ Stillwaterw $^{w}$} \\
\hline & $0.65 \mathrm{a}^{\mathrm{y}}$ & $2^{z}$ & $1.49 \mathrm{a}$ & 1 & $106 \mathrm{a}^{\mathrm{y}}$ & $1^{\mathrm{z}}$ & $346 \mathrm{a}$ & 1 \\
\hline TX88V5440 & $0.44 \mathrm{a}$ & 1 & $1.92 \mathrm{ab}$ & 2 & $320 \mathrm{~b}$ & 4 & $811 \mathrm{~cd}$ & 5 \\
\hline KS84170E-8-3 & $1.07 \mathrm{a}$ & 3 & $2.12 \mathrm{ab}$ & 3 & $315 \mathrm{~b}$ & 3 & $615 b$ & 2 \\
\hline ХH1319 & $2.44 \mathrm{bc}$ & 5 & $2.62 \mathrm{bc}$ & 4 & $389 \mathrm{bc}$ & 5 & $721 \mathrm{bc}$ & 3 \\
\hline OK88W833 & $2.91 \mathrm{bc}$ & 7 & $2.80 \mathrm{bc}$ & 5 & $456 \mathrm{c}$ & 7 & 827 cde & 6 \\
\hline KS87H325-2 & $2.11 \mathrm{~b}$ & 4 & $3.42 \mathrm{~cd}$ & 7 & $310 \mathrm{~b}$ & 2 & 729 bcd & 4 \\
\hline TAM $105^{x}$ & $3.34 \mathrm{~cd}$ & 8 & $3.75 \mathrm{~cd}$ & 9 & $459 \mathrm{c}$ & 8 & 845 cde & 7 \\
\hline TX88V4636 & $2.69 \mathrm{bc}$ & 6 & $3.15 \mathrm{~cd}$ & 6 & $424 \mathrm{c}$ & 6 & $897 \mathrm{de}$ & 9 \\
\hline N87V106 & $4.77 \mathrm{e}$ & 10 & $3.68 \mathrm{~cd}$ & 8 & $627 \mathrm{~d}$ & 10 & $997 \mathrm{e}$ & 10 \\
\hline CO870449 & $4.22 \mathrm{de}$ & 9 & $4.06 \mathrm{~d}$ & 10 & $460 \mathrm{c}$ & 9 & 868 cde & 8 \\
\hline $\operatorname{FLSD}_{(P=0.05)}$ & 1.06 & & 0.90 & & 79 & & 175 & \\
\hline
\end{tabular}

v Calculated following Shaner and Finney's (34) description.

${ }^{w}$ Data are from Pyrenophora tritici-repentis inoculated subplots.

${ }^{x}$ Red Chief and TAM 105 were included as resistant and susceptible check cultivars, respectively.

${ }^{y}$ Means within columns followed by the same letter are not significantly different $(P=0.05)$ following Fisher's least significant difference (FLSD) test.

${ }^{\mathrm{z}}$ Rank among the wheat lines and cultivars was determined by their lesion length values and by their AUDPC values. Rank correlations of lines and cultivars among greenhouse and field trials were significant $(r=0.75$ to $0.93, P \leq 0.05)$. 
surface-disinfested by immersion in a $1 \%$ sodium hypochlorite solution for $30 \mathrm{~s}$, rinsed in deionized water, dried on a paper towel, and placed on moistened filter paper in plastic petri dishes $(100 \times 15 \mathrm{~mm})$. Dishes were then incubated for 2 to 3 days at $21^{\circ} \mathrm{C}$ with alternating 12 -h light and dark periods. After 2 or 3 days, leaves were examined with a stereomicroscope for the presence of conidiophores and conidia of $P$. tritici-repentis.

Disease assessment. Tan spot was visually assessed on approximately 7-day intervals beginning 20 April 1993 using the Horsfall and Barratt rating scale $(13,14)$. Necrotic leaf area due to tan spot was measured from the uppermost fully developed four leaves of four arbitrarily selected tillers per inoculated split-plot. The extent of foliar damage caused by other foliar fungal diseases was minimal at both locations and did not affect tan spot ratings. Final ratings were taken on 13 May and on 19 May 1993 at Stillwater and Perkins, respectively. The area under the disease progress curve (AUDPC) (34) was calculated for each inoculated subplot. Data were subjected to analyses of variance by location following the ANOVA procedure of the SAS statistical program. No disease was present in fungicide-sprayed subplots; subsequently they were deleted from statistical analyses of AUDPC values. Hence, analyses were performed on data from inoculated subplots as a randomized complete block design. Mean separations were done with Fisher's least significant difference test $(P=0.05)$ for AUDPC values (11). Spearman's rank correlation coefficients (36) were calculated using the wheat lines' and cultivars' ranks for tan spot lesion length determined in the two greenhouse trials and AUDPC values from the two field trials.

Yield assessment. Plots were harvested at maturity by cutting $30.5 \mathrm{~cm}$ from the center of each row. Grain yield and kernel weight were determined after hand threshing. Kernel weight was determined by weighing 100 seed from each split-plot. Analyses of variance of plot yield ( $\mathrm{g}$ per plot) and kernel weight (mg per kernel) were done with the ANOVA procedure of SAS. Spearman's rank correlation coefficients were calculated to compare the wheat lines' and cultivars' ranks of lesion length in the greenhouse, their AUDPC assessments determined in the field, and their plot yield and kernel weight ranks derived from the percentage of the $P$. tritici-repentis inoculated subplots compared with fungicide-sprayed subplots.

\section{RESULTS}

Germination of $P$. tritici-repentis conidia on water agar was always greater than $95 \%$ in all greenhouse and field experiments. Statistical analyses showed there was no difference between greenhouse tests for lesion lengths. There were significant dif- ferences $(P=0.05)$ among lines and cultivars in greenhouse trials of lesion lengths, although the lines by trials interaction term was not significant $(P=0.05)$. Data for each greenhouse test were presented separately to demonstrate ranking in relation to field trials. In the two greenhouse trials (Table 1), wheat lines KS84170E-8-3 and TX88V5440 had lesion lengths of 1.07 to $2.12 \mathrm{~mm}$ and 0.44 to $1.92 \mathrm{~mm}$, respectively, and were similar to the cultivar Red Chief, which had lesions 0.65 to $1.49 \mathrm{~mm}$ in length. Lesions on wheat lines KS87H325-2, OK88W833, TX88V4636, and XH1319 were about 2.11 to $3.15 \mathrm{~mm}$ long, which indicated moderate susceptibility to tan spot. Lesions on CO870449 and N87V106 were about 3.68 to $4.77 \mathrm{~mm}$ long, which indicated that these lines were as susceptible to tan spot as the cultivar TAM 105 (Table 1).

Tan spot infection was uniform within all inoculated subplots at both locations of field trials. Low levels ( $<5 \%$ severity) (2) of leaf rust (Puccinia recondita) appeared late in the season in plots not sprayed with propiconazole. $P$. tritici-repentis or other foliar fungi were not cultured from leaves sampled from propiconazole-sprayed subplots. In the analyses of field trial AUDPC values, locations and the lines by trial locations terms were significant. Thus, data were presented for each location. The difference between mean AUDPC values at Perkins and Stillwater (386 and 766, respectively) was significant $(P=0.05)$. AUDPC values were significantly different $(P=0.05)$ among the 10 wheat lines and cultivars in inoculated subplots (Table 1). Red Chief had the lowest AUDPC value at both locations, indicating the greatest resistance to tan spot, which confirms previous reports $(5,11,29)$. AUDPC values of lines KS84170E-8-3, KS87H325-2, and TX88V5440 were about 310 to 320 at Perkins and were more similar to XH1319, which was 389. Although at Perkins, the AUDPC values of TX88V4636, OK88W833, TAM 105, and CO870449 ranged from 424 to 460 , they were similar to XH1319. The differences among wheat lines and cultivars based upon their AUDPC values at Stillwater were not as distinct as their tan spot reactions at Perkins. At Stillwater, the AUDPC values of KS84170E-8-3, XH1319, and
KS87H325-2 were about 615 to 729 . However, at Stillwater, KS87H325-2 was more similar to TX88V5440, OK88W833, TAM 105, and CO870449, which had AUDPC values ranging from 811 to 868 . The AUDPC value of N87V106 at Perkins was 627 and at Stillwater was 997, the highest AUDPC value at both trial locations, indicating it was as susceptible to tan spot as TAM 105.

Rank correlations of the wheat lines and cultivars were highly significant $(r=0.75$ to $0.93, P \leq 0.05$ ) among the two greenhouse and the two field trials from measurements of lesion lengths and the AUDPC values (Table 2). The trial locations and the lines by trial locations term were significant for grain yield $(P=0.05)$; hence the data were presented separately for each location (Table 3). Mean grain yield at Perkins was $74 \mathrm{~g}$ and at Stillwater was 84 g. Grain yield of $P$. tritici-repentis inoculated subplots of the wheat line TX88V4636 was $30 \mathrm{~g}$ lower than that of fungicide-sprayed subplots at Perkins. Grain yield of inoculated subplots of TX885440, OK88W833, TAM 105, and CO870449 was about $20 \mathrm{~g}$ lower than that of their fungicide-sprayed subplots at Stillwater. One exception for grain yield was observed in inoculated subplots at Stillwater. The wheat line KS87H325-2 had about $12 \mathrm{~g}$ higher grain yield in the $P$. tritici-repentis inoculated subplots than in the fungicide-sprayed subplots. Rank correlations among the wheat lines and cultivars, determined as the percentage of inoculated subplot grain yield compared with fungicide-sprayed subplot grain yield, between the two field trial locations was not significant.

There was no significant difference $(P=$ 0.05 ) between trial locations for mean kernel weight. However, there were significant differences $(P=0.05)$ between subplot inoculation and fungicide-sprayed treatments, and the lines by trial locations interaction term was significant for kernel weight. Thus, data of kernel weight were presented for both trial locations (Table 4). Kernel weight at Perkins was reduced about $2.3 \mathrm{mg}$ and at Stillwater was reduced about $4.6 \mathrm{mg}$ in inoculated subplots compared with fungicide-sprayed subplots. Kernel weight of KS84170E-8-3, TAM 105, TX88V4636, N87V106, and

Table 2. Rank correlation coefficients of selected wheat lines from the 1992 Southern Regional Performance Nursery in two greenhouse ratings of tan spot lesion lengths and two tests measuring the area under the disease progress curve (AUDPC) from tan spot inoculation at Zadoks growth stage 31 at two field locations ${ }^{\mathrm{y}}$

\begin{tabular}{lccccc}
\hline & \multicolumn{2}{c}{ Greenhouse experiments } & & \multicolumn{2}{c}{ Ratings of AUDPC } \\
\cline { 2 - 3 } \cline { 5 - 6 } & $\mathbf{1}$ & $\mathbf{2}$ & & Perkins & Stillwater \\
\hline Greenhouse exp. 1 & $\ldots$ & $0.87^{* * z}$ & & $0.93^{* *}$ & $0.79^{* *}$ \\
Greenhouse exp. 2 & & $\ldots$ & & $0.81^{* *}$ & $0.75^{*}$ \\
AUDPC at Perkins & & & & $\ldots$ & $0.89^{* *}$ \\
\hline
\end{tabular}

y Ranks of Red Chief and TAM 105 were included in calculating the Spearman's rank correlation coefficients.

${ }^{\mathrm{z}}$ Correlation coefficients followed by $*$ or $* *$ are significant at $P=0.05$ and $P=0.01$, respectively. 
CO870449 was reduced from 2.5 to $6.7 \mathrm{mg}$ in inoculated subplots at Perkins. Kernel weight of nine lines and cultivars at Stillwater was reduced from 3.2 to $7.8 \mathrm{mg}$ in inoculated subplots. The kernel weight of KS87H325-2 in inoculated subplots was not significantly different from its fungicide-sprayed subplots at Stillwater. Rank correlations among the wheat lines and cultivars, determined as the percentage of inoculated subplot kernel weight compared with fungicide-sprayed subplot kernel weight, between the two field trial locations were not significant $(P=0.05)$.

\section{DISCUSSION}

Rank correlations of wheat lines and cultivars, determined from measurements of $\tan$ spot lesion lengths in greenhouse trials and AUDPC values in field trials, demonstrate that greenhouse screening is a useful technique to screen large numbers of

Table 3. Grain yield of tan spot-inoculated and disease control plots of eight selected lines from the 1992 Southern Regional Performance Nursery over two locations in 1993

\begin{tabular}{|c|c|c|c|c|c|c|}
\hline \multirow[b]{3}{*}{$\begin{array}{l}\text { Wheat lines } \\
\text { and cultivars }\end{array}$} & \multicolumn{6}{|c|}{ Grain yield (g/plot) } \\
\hline & \multicolumn{3}{|c|}{ Perkins $^{\mathrm{w}}$} & \multicolumn{3}{|c|}{ Stillwater $^{w}$} \\
\hline & $\begin{array}{l}\text { Tan spot } \\
\text { inoculated }\end{array}$ & $\begin{array}{c}\text { Fungicide } \\
\text { sprayed }\end{array}$ & $\operatorname{Rank}^{x}$ & $\begin{array}{c}\text { Tan spot } \\
\text { inoculated }\end{array}$ & $\begin{array}{l}\text { Fungicide } \\
\text { sprayed }\end{array}$ & Rank $^{x}$ \\
\hline Red Chief ${ }^{y}$ & 52.4 & 64.6 & 3 & 52.2 & 63.3 & 6 \\
\hline TX88V5440 & 72.6 & 84.5 & 2 & $86.2 \mathrm{a}$ & $110.4 \mathrm{~b}$ & 7 \\
\hline KS84170E-8-3 & 76.4 & 97.5 & 6 & 80.7 & 98.9 & 8 \\
\hline XH1319 & 62.7 & 78.9 & 7 & 90.1 & 98.2 & 2 \\
\hline OK88W833 & 80.2 & 100.2 & 5 & $98.6 \mathrm{a}$ & $118.0 \mathrm{~b}$ & 5 \\
\hline KS87H325-2 & 69.5 & 70.6 & 1 & $83.3 \mathrm{a}$ & $70.7 \mathrm{~b}$ & 1 \\
\hline TAM $105^{y}$ & 68.5 & 93.7 & 8 & $60.2 \mathrm{a}$ & $99.7 \mathrm{~b}$ & 10 \\
\hline TX88V4636 & $59.5 \mathrm{a}$ & $91.1 \mathrm{~b}$ & 10 & 76.0 & 85.2 & 4 \\
\hline N87V106 & 62.5 & 83.9 & 9 & 70.3 & 79.8 & 3 \\
\hline CO870449 & 52.1 & 64.5 & 4 & $69.1 \mathrm{a}$ & $97.7 \mathrm{~b}$ & 9 \\
\hline $\operatorname{FLSD}_{(P=0.05)}$ & $15.7^{\mathrm{z}}$ & 23.9 & & 21.7 & 29.1 & \\
\hline
\end{tabular}

${ }^{\mathrm{w}}$ Means within rows of each location followed by different letters are significantly different $(P=$ $0.05)$ using the standard error $\left(2 E_{b} / r\right)^{-1 / 2}$ for the pair comparison of two subplot means at the same main plot treatment to compute the least significant difference. Means within rows of each location without letters are not significantly different from each other.

${ }^{\mathrm{x}}$ Rank among the wheat lines and cultivars was derived from the percentage of inoculated subplot grain yield compared with fungicide-sprayed subplot grain yield. Rank correlation between the two field trial locations was not significant.

${ }^{y}$ Red Chief and TAM 105 were included as tan spot-resistant and -susceptible cultivars, respectively.

${ }^{\mathrm{z}}$ Fisher's least significant difference (FLSD) values are included to compute differences among lines and cultivars within columns.

Table 4. Kernel weight of tan spot inoculated and disease control plots of eight selected lines from the 1992 Southern Regional Performance Nursery over two locations in 1993

\begin{tabular}{|c|c|c|c|c|c|c|}
\hline \multirow[b]{3}{*}{$\begin{array}{l}\text { Wheat lines } \\
\text { and cultivars }\end{array}$} & \multicolumn{6}{|c|}{ Kernel weight (mg/kernel) } \\
\hline & \multicolumn{3}{|c|}{ Perkins $^{\mathrm{w}}$} & \multicolumn{3}{|c|}{ Stillwater $^{w}$} \\
\hline & $\begin{array}{l}\text { Tan spot } \\
\text { inoculated }\end{array}$ & $\begin{array}{c}\text { Fungicide } \\
\text { sprayed }\end{array}$ & $\operatorname{Rank}^{x}$ & $\begin{array}{l}\text { Tan spot } \\
\text { inoculated }\end{array}$ & $\begin{array}{l}\text { Fungicide } \\
\text { sprayed }\end{array}$ & $\operatorname{Rank}^{\mathbf{x}}$ \\
\hline Red Chief ${ }^{y}$ & 30.8 & 31.3 & 5 & $28.5 \mathrm{a}$ & $32.3 \mathrm{~b}$ & 3 \\
\hline TX88V5440 & 27.5 & 27.3 & 1 & $25.5 \mathrm{a}$ & $28.8 \mathrm{~b}$ & 5 \\
\hline KS84170E-8-3 & $33.0 \mathrm{a}$ & $35.5 \mathrm{~b}$ & 6 & $29.3 \mathrm{a}$ & $33.5 \mathrm{~b}$ & 4 \\
\hline XH1319 & 31.3 & 32.0 & 4 & $31.8 \mathrm{a}$ & $35.0 \mathrm{~b}$ & 2 \\
\hline OK88W833 & 34.5 & 34.8 & 2 & $31.8 \mathrm{a}$ & $36.0 \mathrm{~b}$ & 6 \\
\hline KS87H325-2 & 27.8 & 28.0 & 3 & 29.3 & 30.3 & 1 \\
\hline TAM $105^{y}$ & $23.3 \mathrm{a}$ & $30.0 \mathrm{~b}$ & 10 & $21.0 \mathrm{a}$ & $28.5 \mathrm{~b}$ & 10 \\
\hline TX88V4636 & $27.3 \mathrm{a}$ & $32.0 \mathrm{~b}$ & 9 & $25.5 \mathrm{a}$ & $31.3 \mathrm{~b}$ & 8 \\
\hline N87V106 & $27.0 \mathrm{a}$ & $30.3 \mathrm{~b}$ & 7 & $25.5 \mathrm{a}$ & $30.3 \mathrm{~b}$ & 7 \\
\hline CO870449 & $25.5 \mathrm{a}$ & $29.5 \mathrm{~b}$ & 8 & $25.5 \mathrm{a}$ & $33.3 \mathrm{~b}$ & 9 \\
\hline $\operatorname{FLSD}_{(P=0.05)}$ & $2.3^{\mathrm{z}}$ & 2.1 & $\ldots$ & 3.2 & 2.9 & $\ldots$ \\
\hline
\end{tabular}

${ }^{\mathrm{w}}$ Means within rows of each location followed by different letters are significantly different $(P=$ $0.05)$ using the standard error $\left(2 E_{b} / r\right)^{-1 / 2}$ to compute the least significant difference for the pair comparison of two subplot means at the same main plot treatment. Means within rows of each location without letters are not significantly different from each other.

${ }^{\mathrm{x}}$ Rank among wheat lines and cultivars was derived from percent inoculated subplot kernel weight compared with fungicide-sprayed subplot kernel weight. Rank correlation between the two field trial locations was not significant.

${ }^{y}$ Red Chief was included as a tan spot-resistant cultivar; TAM 105 was included as a tan spot-susceptible cultivar

${ }^{\mathrm{z}}$ Fisher's least significant difference (FLSD) values are included to compute differences among lines and cultivars within columns. wheat lines for reaction to tan spot. Also, the greenhouse screening of wheat lines for reaction to tan spot provided a good indication of a prospective wheat line's reaction to tan spot in the field as determined by its AUDPC value. Having the ability to screen for resistance to tan spot in the greenhouse increases the number of lines that can be tested through time to identify potential sources of resistance in a wheat breeding program. We found that greenhouse measurements of tan spot lesion length and AUDPC values measured in field trials (Table 1) did not adequately predict differences that were observed in the field regarding the grain yields and kernel weights (Tables 3 and 4) that were assessed in inoculated subplots of wheat lines and cultivars. For example, KS84170E-8-3 had short tan spot lesion lengths in both greenhouse trials and low AUDPC values at Perkins and Stillwater; yet the grain yield in inoculated subplots, as a percentage of the fungicide-sprayed subplot yield, was ranked among the highest at Perkins and among the lowest at Stillwater. However, these tests did allow us to identify lines such as KS87H325-2, which had intermediate tan spot lesion length and low to intermediate AUDPC values, yet had grain yield and kernel weight values in inoculated subplots that were equal to the fungicide-sprayed subplot values at Perkins and Stillwater. Mean grain yield of inoculated subplots was 15 to $17 \%$ less than that of the fungicidesprayed subplots. Mean kernel weight in inoculated subplots was reduced $7 \%$ at Perkins and $13 \%$ at Stillwater. However, rank correlations of wheat lines and cultivars between Perkins and Stillwater for grain yield and kernel weight, derived as the percentage of the inoculated subplot measurements compared with fungicidesprayed subplots, were not significant. Thus, although mean lesion length assessed on seedlings in the greenhouse provided a good approximation of AUDPC values that were measured in the field, assessments of susceptible tan spot reaction did not provide an indication of the extent tan spot would reduce grain yields and kernel weights in inoculated subplots of individual lines or cultivars. One explanation for this is that influences such as nutrients, availability of moisture, temperature, and their interactions with the genetic background of the host line or cultivar can have a greater influence on grain yield and kernel weight than the effect of disease alone (35).

In our studies, initiation of tan spot was achieved in the field using laboratory-cultured conidia of three $P$. tritici-repentis isolates. We believe misting, which maintained free moisture on wheat foliage, was critical to the successful establishment of tan spot. Further, use of this system allowed the initiation of tan spot at a specific time in the growing season, which is ad- 
vantageous over relying on weather conditions to mature pseudoperithecia of $P$. tritici-repentis on oat kernels or wheat straw. In a previous study, Brûlé-Babel and Lamari (7) reported that mist-irrigation was more practical than the use of plastic tenting to provide a postinoculation environment suitable for screening large-scale wheat breeding nurseries, although statistical analysis of their data was not provided. In addition to describing a mist-irrigation system that is simple to assemble and use, our results confirm this observation and demonstrate that seedling tests conducted in the greenhouse can be used to screen large numbers of wheat lines for reaction to tan spot, from which promising lines can then be evaluated in field trials.

\section{ACKNOWLEDGMENTS}

Funding from the Oklahoma Wheat Research Foundation and the Oklahoma Agricultural Experiment Station is gratefully acknowledged. Special thanks are extended to Rocky M. Walker for assistance throughout these tests. Approved for publication by the Director, Oklahoma Agricultural Experiment Station. This research was supported under project $\mathrm{H}-1871$.

\section{LITERATURE CITED}

1. Adee, E. A., and Pfender, W. F. 1989. The effect of primary inoculum level of Pyrenophora tritici-repentis on tan spot epidemic development in wheat. Phytopathology 79:873-877.

2. Anonymous. Rust Scoring Guide. International Maize and Wheat Improvement Center. Londres 40, Apdo. Postal 6-641, Mexico 06600, D. F., Mexico.

3. Ballance, G. M., Lamari, L., and Bernier, C. C. 1988. Isolation and characterization of the toxin of Pyrenophora tritici-repentis, the causal agent of tan spot of wheat. (Abstr.) Phytopathology 78:1527.

4. Bockus, W. W., and Claassen, M. M. 1992. Effects of crop rotation and residue management practices on severity of tan spot of winter wheat. Plant Dis. 76:633-636.

5. Bockus, W. W., and Tomas, A. 1987. Field reaction of selected winter wheat cultivars to tan spot, 1986. Biol. Cult. Tests Control Plant Dis. 2:43.

6. Brown, D. A., and Hunger, R. M. 1992. Production of a chlorosis-inducing, host-specific, low-molecular weight toxin by isolates of $P y$ renophora tritici-repentis, cause of tan spot of wheat. J. Phytopathol. 137:221-232.

7. Brûlé-Babel, A. L., and Lamari, L. 1992. Evaluation of field screening techniques for tan spot resistance in spring wheat. Pages 3943 in: Advances in tan spot research: Proceedings of the 2nd International Tan Spot Workshop. L. J. Francl, J. M. Krupinsky, and M. P. McMullen, eds. North Dakota State University, Fargo.

8. Cox, D. J., and Hosford, R. M., Jr. 1987.
Resistant winter wheats compared at differing growth stages and leaf positions for tan spot severity. Plant Dis. 71:883-886.

9. Diaz de Ackermann, M., Hosford, R. M., Jr., Cox, D. J., and Hammond, J. J. 1988. Resistance in winter wheats to geographically differing isolates of Pyrenophora tritici-repentis and observations on pseudoperithecia. Plant Dis. 72:1028-1031.

10. Evans, C. K., Hunger, R. M., and Siegerist, W. C. 1993. Enhanced production of Pyrenophora tritici-repentis conidial suspensions. Plant Dis. 77:981-984.

11. Evans, C. K., Hunger, R. M., and Siegerist, W. C. 1993. Reaction of the Southern Regional Performance nursery to tan spot, 1992. Biol. Cult. Tests Control Plant Dis. 8:92.

12. Fernandez, M. R., Clarke, J. M., DePauw, R. M., Irvine, R. B., and McLeod, J. G. 1992. Evaluation of durum wheat for resistance to tan spot and pink smudge. Pages 28-32 in: Advances in tan spot research: Proceedings of the 2nd International Tan Spot Workshop. L. J. Francl, J. M. Krupinsky, and M. P. McMullen, eds. North Dakota State University, Fargo.

13. Horsfall, J. G., and Barratt, R. W. 1945. An improved grading system for measuring plant diseases. Phytopathology 35:655.

14. Horsfall, J. G., and Cowling, E. B. 1978. Pathometry: The measurement of plant disease. Pages 119-136 in: Plant Disease, An Advanced Treatise. Vol. II. J. G. Horsfall and E. B Cowling, eds. Academic Press, New York

15. Hosford, R. M., Jr. 1971. A form of Pyrenophora trichostoma pathogenic to wheat and other grasses. Phytopathology 61:28-32.

16. Hosford, R. M., Jr., and Busch, R. H. 1974. Losses in wheat caused by Pyrenophora trichostoma and Leptosphaeria avenaria $\mathrm{f}$. sp. triticea. Phytopathology 64:184-187.

17. Hosford, R. M., Jr., Jordahl, J. G., and Hammond, J. J. 1990. Effect of wheat genotype, leaf position, growth stage, fungal isolate, and wet period on tan spot lesions. Plant Dis. 74:385-390.

18. Hosford, R. M., Jr., Larez, C. R., and Hammond, J. J. 1987. Interaction of wet period and temperature on Pyrenophora tritici-repentis infection and development in wheats of differing resistance. Phytopathology 77:10211027.

19. Howard, R. J., and Morrall, R. A. A. 1975. The epidemiology of leaf spot in a native prairie. I. The progression of disease with time. Can. J. Bot. 53:1040-1050.

20. Krupinsky, J. M. 1982. Observations on the host range of isolates of Pyrenophora trichostoma. Can. J. Plant Pathol. 4:42-46.

21. Krupinsky, J. M. 1986. Pyrenophora triticirepentis, $P$. bromi, and Leptosphaeria nodorum on Bromus inermus in the Northern Great Plains. Plant Dis. 70:61-64.

22. Krupinsky, J. M. 1987. Pathogenicity on wheat of Pyrenophora tritici-repentis isolated from Bromus inermis. Phytopathology 77:760-765.

23. Krupinsky, J. M. 1992. Aggressiveness of Pyrenophora tritici-repentis isolated from grass and barley hosts. Plant Dis. 76:783-789.

24. Krupinsky, J. M. 1992. Grass hosts of $P y$ renophora tritici-repentis. Plant Dis. 76:8791.

25. Lamari, L., and Bernier, C. C. 1989. Evaluation of wheat lines and cultivars to tan spot [Pyrenophora tritici-repentis] based on lesion type. Can. J. Plant Pathol. 11:49-56.

26. Lamari, L., and Bernier, C. C. 1989. Toxin of Pyrenophora tritici-repentis: Host specificity, significance in disease, and inheritance of host reaction. Phytopathology 79:740-744.

27. Lamari, L., and Bernier, C. C. 1991. Genetics of tan necrosis and extensive chlorosis in tan spot of wheat caused by Pyrenophora triticirepentis. Phytopathology 81:1092-1095.

28. Lamari, L., Bernier, C. C., and Smith, R. B. 1991. Wheat genotypes that develop both tan necrosis and extensive chlorosis in response to isolates of Pyrenophora tritici-repentis. Plant Dis. 75:121-122.

29. Raymond, P. J., Bockus, W. W., and Norman, B. L. 1985. Tan spot of winter wheat: Procedures to determine host response. Phytopathology 75:686-690.

30. Rees, R. G., Platz, G. J., and Meyer, R. J. 1982. Yield losses in wheat from yellow spot: Comparison of estimates derived from single tillers and plots. Aust. J. Agric. Res. 33:899908.

31. Riaz, M., Bockus, W. W., and Davis, M. A. 1991. Effects of wheat genotype, time after inoculation, and leaf age on conidia production by Drechslera tritici-repentis. Phytopathology 81:1298-1302.

32. Schilder, A. M. C., and Bergstrom, G. C. 1994 Infection of wheat seed by Pyrenophora triticirepentis. Can. J. Bot. 72:510-519.

33. Shabeer, A., and Bockus, W. W. 1988. Tan spot effects on yield and yield components relative to growth stage in winter wheat. Plant Dis. 72:599-602.

34. Shaner, G., and Finney, R. E. 1977. The effect of nitrogen fertilization on the expression of slow-mildewing resistance in Knox wheat. Phytopathology 67:1051-1056.

35. Simmonds, N. W. 1979. Principles of Crop Improvement. Longman Inc., New York. pp. 41-50.

36. Snedecor, G. W., and Cochran, W. G. 1989 Statistical Methods. 8th ed. Iowa State University, Ames.

37. Tomas, A and Bockus, W. W. 1987. Cultivar specific toxicity of culture filtrates of Pyrenophora tritici-repentis. Phytopathology 77:1337-1340.

38. Vanterpool, T. C. 1963. Pink and smudgepink discoloration of wheat seed associated with the yellow leaf spot disease (Drechslera tritici-repentis). Proc. Can. Phytopathol. Soc. 30:19-20.

39. Weis, M. V. 1987. Compendium of Wheat Diseases. 2nd ed. American Phytopathological Society, St. Paul, MN. pp. 42-46.

40. Zadoks, J. C., Chang, T. T., and Konzak, C. F. 1974. A decimal code for the growth stages of cereals. Weed Res. 14:415-421.

41. Zadoks, J. C., and Schein, R. D. 1979. Epidemiology and Plant Disease Management. Oxford University, New York. pp. 163-165. 